Kohl: a Journal for Body and Gender Research Vol. 3, No. 2 (Winter 2017)

\title{
Love in the Time of Limp Dicks
}

Sophie Chamas 


\section{Diagnose Me}

I ask my boyfriend to leave the house twenty minutes before I am meant to Skype call my therapist. Enough time to ensure he is long gone before I unfasten the muzzle securing my mind's mouth and start secreting psychic saliva, smelling of my crazy.

I live in Dubai, which my therapist recently left, like most of its denizens eventually do. She is back in her native Belgium. I don't know where exactly. I never bother to ask. She traded stability for home, I guess, like I hope all of this non-place's privileged expatriates eventually will. Does stability bring anything but numbness? I guess she realized money and security can't cure restlessness.

Dubai really can build anything. Faux islands. British pubs complete with crass British bar managers who won't let you bring your own damn peanuts into their snack-less hole-in-the-wall. Indoor ski slopes complete with penguins sucking you so deep into pretend you forget there is no air to inhale beyond this ice dome, beyond the mall, beyond the air-conditioned four-by-four. It can't build familiarity though. Can't fake the visceral. Can't sow onto my nerve endings that feeling that comes from having sat in a place that has been sitting with itself for a long time.

So we Skype, my therapist and I. I tell her I can't get out of my own head long enough to let myself be honest to god fucked. Whatever that means. She laughs. I ask her not to diagnose me with Arabness or Muslimness or any other kind of social guilt, pre-empting a conversation that might turn me off and ruin our arrangement. My mom takes me to the gynaecologist for pap smears and STI tests and asks me about penis sizes. She is not a liberal or a leftist or a feminist or a self-loathing Lebanese/Muslim/Shi'ite. She is just my mom. She doesn't explain herself with ideological whys and moral becauses. She just gave me what she didn't have.

My therapist asks why I blame myself, why I think my parts don't work right, my sex is broken, my body doesn't know how to feel. She says I just haven't met the "right" person yet, the person who will know how to fuck me. Who will know how to fuck the noise out of my head or the quiet into it. Who will stroke the thoughts like hairs away from my face and tuck them behind into temporary silence deep in muffling pillow, allowing me to feel something without commentary. Later in life, I will discover Lacan, and learn that all desire is pseudo, a shoddy replacement for an unreachable real, and I will finally relax into my skin, my genitals, my life choices. I will realize that I am waiting for no one but myself to grasp fantasy as lifeline, longing as respirator, and dissatisfaction as a propeller forever forward into new becomings.

\section{Love me like Mr. Darcy, Fuck me Like Gaspar Noé is Filming}

I have never been fucked. Not in that raw, animalistic, bodies colliding, writhing, gyrating way that porn glorifies. I have never been made love to either, in that Jane Austen, Brontë sisters kind of way, all body and soul, transfix me quite, choreographed hands, lips, feet, where all flaws melt into air and there is no semen, no quiffs and farts and bumping heads and body hair in weird places and balls slapping against ass cheeks the feel of which you hate yourself for liking. What is less romantic than testicles. 
I have only ever had sex. Just an in and out and now you're done and don't forget about me and okay rub until I feel that pinch of pleasure, but just a pinch, no loss of control, clenched the entire time because you have given me no reason to loosen my insides - figuratively, metaphorically, what the fuck is the difference?

I don't even know if I care for sex. I loved someone once. He was impotent with me. I am still not quite sure why. But I think I could have spent a lifetime with him just cupping my face the way he did, like he was going to drink up every one of my features, like we only had that one chance to be together, like for a second it didn't matter that for some reason I brought out the limp dick in him, and whatever that said about him and me and this pressure the world puts on us to be certain kinds of lovers.

He kept his t-shirt on. Maybe because he was so skinny. His bony pelvis would press against my fleshier thighs. At some point we stopped trying. I stopped feeling for it. He would keep his underwear on. And we would just rub against each other. All of our energy, all of that love and angst and fear I guess, concentrated in the space between our faces, in the gaps between his palms and my cheeks, in the tight pockets of air between our lips pressing together aggressively in temper tantrum kisses acting out their frustration with the enervated elephant in the room.

My therapists always want to talk about him. I am all talked out though. Not every relationship comes with closure and what was left vague and weird and fucked up when he released his grip from my face remains that way, years later, and no amount of talking it or the series of bad decisions I made in its wake through will bring me closer to any one of the world's working definitions of normal. I loved him and he loved me and something about the way I loved him and he loved me literally paralyzed his so-called love organ. Emasculated him. Plopped him raw, floppy, disgraced in front of the cavity leading to our intimacy, incapable of even crawling in.

\section{They May Only Visit in the Shower}

I masturbate to the memories of men I never wanted to fuck. Outside of the shower, I shake intrusive thoughts of them out of my head, my body squirming with reminders of a revulsion towards an intimacy I never wanted.

But in the shower, my thighs relax in anticipation of getting off on the memory of sex that once disgusted me. I turn and twist my basic bitch of a showerhead, closing my eyes tightly in faux-tantric concentration as I try to isolate images of past sex acts from the feelings that soured them.

There is something about recreating it after having gotten away, after having released from my hips the desperate grip of desperate men whose loving I solicited as an antidote to a self-loathing they only deepened, like a dirty fingernail picking away at an ingrown hair.

There is something about the water beating against and alongside the image and sound of their balls excitedly slapping against my ass, my insides clogged with the weight of their until now unquenched desire for sexual gratification, their undesirability peeling off their dicks like scabs, chafing my vaginal wall. 
The water mutes the repulsion, or maybe it amplifies it to the point of eroticism. I am not quite sure. I am not sure what I would rather be convinced of.

\section{Horny for Your Politics}

She was little more than an Instagram story.

She creamed in her panties, though, when she spotted you looking all disheveled-like, hirsute, a big man whose every curve and fold of flesh seems like confidence forcing itself into visible presence - a greasy middle finger up to the beauty standards that designate social capital in this mind-forsaken country.

She must have noticed your disdain for most of human and canine kind compressed within your folded arms, loosened only to dismiss with an uncharacteristically gentle wave of hand everything everyone says or likes or does.

Socialist chic would look great on Instagram. A little bit of the radical, a little bit of fuck me Marx, would do wonders to the self she was piecing together through socio-cultural shock and awe.

Two fingers spread wide, stiletto nailed, and painted disco-ball kitsch, framing a sickle and hammer.

Think of the likes. Think of the gasps. Think of the offended and aroused.

Yeah, she was horny for your politics. She wanted to offend and arouse. She was both a someone and a no one - a human mood ring shifting to match changing shades of cool.

But I am not a performance. We have one thing in common though, her and I - a hunger for lumberjack masculinity made acceptable by good politics - fuck us doggy style, spank our fleshy asses, pinch our tiny waists red, and bruise our nipples without making us hate ourselves. But I am not a performance. 